\begin{tabular}{lr}
\hline Chemistry of & Chem. Met. Alloys 5 (2012) 148-154 \\
Melals and Alloys & Ivan Franko National University of Lviv \\
www.chemetal-journal.org
\end{tabular}

\title{
Crystal and electronic structure of $\mathrm{La}_{2} \mathrm{LiAlGe}_{2}$
}

\author{
Andrij STETSKIV ${ }^{1 *}$, Ivan TARASIUK ${ }^{2}$, Volodymyr PAVLYUK $^{2}$ \\ ${ }^{1}$ Department of Chemistry, Ivano-Frankivsk National Medical University, \\ Galytska St. 2, 76018 Ivano-Frankivsk, Ukraine \\ ${ }^{2}$ Department of Inorganic Chemistry, Ivan Franko National University of Lviv, \\ Kyryla i Mefodiya St. 6, 79005 Lviv, Ukraine \\ * Corresponding author.Tel.: +380-342-58272; e-mail: andrij_stetskiv69@mail.ru
}

Received December 11, 2012; accepted December 26, 2012; available on-line July 5, 2013

The new quaternary dilanthanum lithium aluminum digermanide $\mathrm{La}_{2} \mathrm{LiAlGe}_{2}$ crystallizes with a structure derivative of the orthorhombic $\alpha-\mathrm{GdSi}_{2}$, tetragonal $\alpha-\mathrm{ThSi}_{2}$ and $\mathrm{LaPtSi}$ types. The relations between these structures are described by a group-subgroup scheme on the basis of Bärnighausen formalism. The crystal structure consists of six crystallographically distinct atom sites in Wyckoff positions $2 a$ and $2 b$ (space group Imm2), site symmetry $m m 2$. The La atoms are surrounded by 20 -vertex Frank-Kasper polyhedra. The germanium, lithium and aluminum atoms are coordinated by tricapped trigonal prisms. The bonding between the atoms was explored by means of the TB-LMTO-ASA (tight-binding linear muffin-tin orbital atomic spheres approximation) method. The highest electron concentration is around Ge. The density of states at the Fermi level indicates metallic behavior.

Intermetallic compound / Crystal structure / Electronic structure / Rare earth elements / Lithium

\section{Introduction}

The REAlGe $(R E=$ rare earth elements $)$ ternary germanides crystallize in the tetragonal LaPtSi structure type with space group $I 4_{1} m d$ [1-5]. The ternary LaPtSi type is an ordered superstructure of $\alpha-\mathrm{ThSi}_{2}$, space group I4 1 /amd, $a=4.126, c=14.346 \AA$ [6]. The latter structure type is adopted by the binary compound $\mathrm{LaGe}_{2}-\mathrm{HT}$ [7] and the ternary phase $\mathrm{Ce}(\mathrm{Li}, \mathrm{Si})_{2}$ from the Ce-Li-Si system [8]. The formation of ternary compounds with $\mathrm{LaPtSi}$ or $\alpha-\mathrm{ThSi}_{2}$ structure types is not observed in the $R E-\mathrm{Li}-\mathrm{Ge}$ ternary systems [9-14]. The room temperature modification of $\mathrm{LaGe}_{2}$ (LT-phase) crystallizes in the orthorhombic $\alpha-\mathrm{GdSi}_{2}$ type with space group Imma [15].

\section{Experimental section}

Lanthanum, lithium, aluminum, and germanium, all with a nominal purity of more than 99.9 wt.\%, were used as starting elements for the preparation of alloys. Pieces of the pure metals were pressed into a pellet, which was enclosed in a tantalum crucible and placed in a resistance furnace with a thermocouple controller. The heating rate from room temperature to $670 \mathrm{~K}$ was
$5 \mathrm{~K}$ per minute. At this temperature the alloy was held for two days and then the temperature was increased from 670 to $1070 \mathrm{~K}$ over $1 \mathrm{~h}$. The alloy was annealed at this temperature for $8 \mathrm{~h}$ and slowly cooled down to room temperature. After the melting and annealing procedures, the total weight loss was less than $2 \%$. A small $(0.07 \times 0.05 \times 0.01 \mathrm{~mm})$, good-quality single crystal of the title compound was isolated from the alloy.

Single-crystal data were collected at room temperature by using a four-circle diffractometer (Xcalibur Oxford Diffraction diffractometer) with a CCD detector (graphite monochromatized Mo Ka radiation, $\lambda=0.71073 \AA$ ). Scans were taken in the $\omega$ mode, analytical absorption corrections were made with CrysalisRed [16]. The crystal structure of the quaternary compound investigated in the present work was successfully solved by direct methods and refined using SHELX-97 package programs [17].

The $\mathrm{La}_{2} \mathrm{LiAlGe}_{2}$ alloy was studied by Wavelength Dispersive Spectrometry (WDS) and Electron Probe Microanalysis (EPMA) on a CAMECA SX-100 device. The molar proportions of lanthanum, aluminum and germanium were obtained this way; the lithium content was calculated by difference. The resulting composition was $\mathrm{La}_{33.4(1)} \mathrm{Li}_{15.3} \mathrm{Al}_{17.4(5)} \mathrm{Ge}_{33.9(2)}$ (atomic percent). The content of lithium was 
experimentally determined from a solution of $150 \mathrm{mg}$ alloy in $25 \mathrm{ml} 1 \mathrm{M} \mathrm{HCl}$ by means of a Flapho-4 flame photometer (Carl Zeiss Jena) using an interference filter $(671 \mathrm{~nm})$. The measured value was $87.4 \mathrm{mg} / 1$ of lithium, which corresponds to 15.9 at.\% in the alloy.

\section{Results and discussion}

During a systematic study of quaternary alloys of the La-Li-Al-Ge system we detected a $\mathrm{LaLi}_{x} \mathrm{Al}_{1-x} \mathrm{Ge}$ limited solid solution in the LaAlGe-LaLiGe concentration section. The powder diffraction patterns indicated that the alloys were single phase up to $x=0.5$. To explain the formation mechanism of the solid solution we decided to further study this phase using the single-crystal method. Structure data and details of the data collection are presented in Table 1. The structure was solved after an analytical absorption correction. At the first stage of the structure solution, the positions of $\mathrm{La}, \mathrm{Ge}, \mathrm{Al}$ and $\mathrm{Li}$ atoms were obtained by direct methods. However, the Al (in 2a) and $\mathrm{Li}$ (in $2 b$ ) positions showed thermal displacement parameter considerably different from those of the other atoms, suggesting that these positions are partially occupied by $\mathrm{Li}$ and $\mathrm{Al}$ atoms. The refinement of the occupancies indicated that there is about $70 \%$ $\mathrm{Al}$ and $30 \% \mathrm{Li}$ atoms on the $2 a$ site, and vice versa on the $2 b$ site. The difference between the $\mathrm{Al} / \mathrm{Li}$ ratio on these sites is probably the cause of the lowering of the symmetry to space group Imm 2 from $I 4_{1} /$ amd, $I 4_{1} m d$ or Imma, adopted by related structures. Attempts to refine the title structure in tetragonal $I 4_{1} / \mathrm{amd}, I 4_{1} \mathrm{md}$ and $I 4_{1}$ or orthorhombic Imma space groups were unsuccessful. For space groups $I 4_{1} /$ amd and $I 4_{1} m d$, among the 693 observed reflexes, 22 should be systematically absent. For space group $I 4_{1}$, the two reflections 006 and $00-6$ violate the conditions for systematic absences.

The obtained single-crystal data show that the title compound crystallizes with the orthorhombic space group Imm 2 in a structure derived from the $\alpha-\mathrm{GdSi}_{2}$, $\alpha-\mathrm{ThSi}_{2}$ and LaPtSi types. The refined fractional atomic coordinates and displacement parameters are given in Table 2. A projection of the unit cell and coordination polyhedra of the atoms is shown in Fig. 1. The interatomic distances are listed in Table 3. The 20-vertex Frank-Kasper polyhedra are typical for La atoms. The germanium, aluminum and lithium atoms are enclosed in trigonal prisms. The packing of trigonal prisms is shown in Fig. 2. Since the title phase is pseudo tetragonal, as said above, structure refinements were also carried out in the possible tetragonal models. However, the best results were obtained for space group Imm2. Fig. 3 shows the relations between the possible tetragonal and orthorhombic structure models in a group-subgroup scheme on the basis of Bärnighausen formalism [19].

Table 1 Crystal data and details of the structure refinement of $\mathrm{Al}_{1.04} \mathrm{Ge}_{2} \mathrm{La}_{2} \mathrm{Li}_{0.96}$.

\begin{tabular}{c|c}
\hline Molar mass $(\mathrm{g} / \mathrm{mole})$ & 915.52 \\
Crystal system & orthorhombic \\
Space group & Imm2 \\
Pearson symbol & oS12 \\
Unit cell dimension $a(\AA)$ & $4.3459(4)$ \\
Unit cell dimension $b(\AA)$ & $4.3461(5)$ \\
Unit cell dimension $c(\AA)$ & $14.792(3)$ \\
Unit cell volume $\left(\AA^{3}\right)$ & $279.39(7)$ \\
Formula units per cell & 2 \\
Calculated density $\left(\mathrm{g} / \mathrm{cm}^{3}\right)$ & 5.441 \\
Absorption coefficient $\left(\mathrm{mm}^{-1}\right)$ & 25.63 \\
$F(000)$ & 389 \\
$\theta$ range for data collection $\left(^{\circ}\right)$ & $2.8-27.7$ \\
Range in $h k l$ & $-5 \leq h \leq 5$ \\
& $-5 \leq k \leq 5$ \\
Total number of reflections & $-16 \leq l \leq 18$ \\
Independent reflections & 889 \\
Reflections with $I>2 \sigma(I)$ & 353 \\
Data/parameters & 285 \\
Goodness-of-fit on $F^{2}$ & $353 / 24$ \\
$R\left[F^{2}>2 \sigma\left(F^{2}\right)\right]$ & 1.16 \\
$w R\left(F^{2}\right)$ & 0.040 \\
Largest peak and hole $\left(\mathrm{e} / \AA^{3}\right)$ & 0.107 \\
Flack parameter $[18]$ & $2.35 /-1.77$ \\
\hline
\end{tabular}




\section{A. Stetskiv et al., Crystal and electronic structure of $\mathrm{La}_{2} \mathrm{LiAlGe}_{2}$}

Table 2 Fractional atomic coordinates and displacement parameters $\left(\AA^{2}\right)$.

\begin{tabular}{c|c|c|c|c|c|c}
\hline Atom & Site & $x / a$ & $y / b$ & $z / c$ & $U_{\text {iso }} * / U_{\text {eq }}$ & Occ. $(<1)$ \\
\hline La1 & $2 a$ & 0 & 0 & $0.58335(13)$ & $0.0089(6)$ & \\
La2 & $2 b$ & 0 & $1 / 2$ & $0.83320(14)$ & $0.0072(6)$ & \\
Ge3 & $2 a$ & 0 & 0 & $0.0001(3)$ & $0.0140(12)$ & \\
Ge4 & $2 b$ & 0 & $1 / 2$ & $0.2500(3)$ & $0.0170(14)$ & $0.1663(19)$ \\
A15 & $2 a$ & 0 & 0 & $0.1663(19)$ & $0.040(11)^{*}$ & $0.69(6)$ \\
Li5 & $2 a$ & 0 & 0 & $0.435(4)$ & $0.040^{*}$ & $0.35(5)$ \\
A16 & $2 b$ & 0 & $1 / 2$ & $0.435(4)$ & $0.040^{*}$ & 0.65 \\
Li6 & $2 b$ & 0 & $1 / 2$ & $U_{12}$ & $U_{13}$ & $U_{23}$ \\
\hline & $U_{11}$ & $U_{22}$ & $U_{33}$ & 0 & 0 \\
La1 & $0.0060(11)$ & $0.0068(10)$ & $0.0139(12)$ & 0 & 0 & 0 \\
La2 & $0.0093(12)$ & $0.0081(10)$ & $0.0043(10)$ & 0 & 0 & 0 \\
Ge3 & $0.018(2)$ & $0.0130(19)$ & $0.011(3)$ & 0 & 0 & 0 \\
Ge4 & $0.017(2)$ & $0.018(2)$ & $0.016(3)$ & 0 & & 0 \\
\hline
\end{tabular}

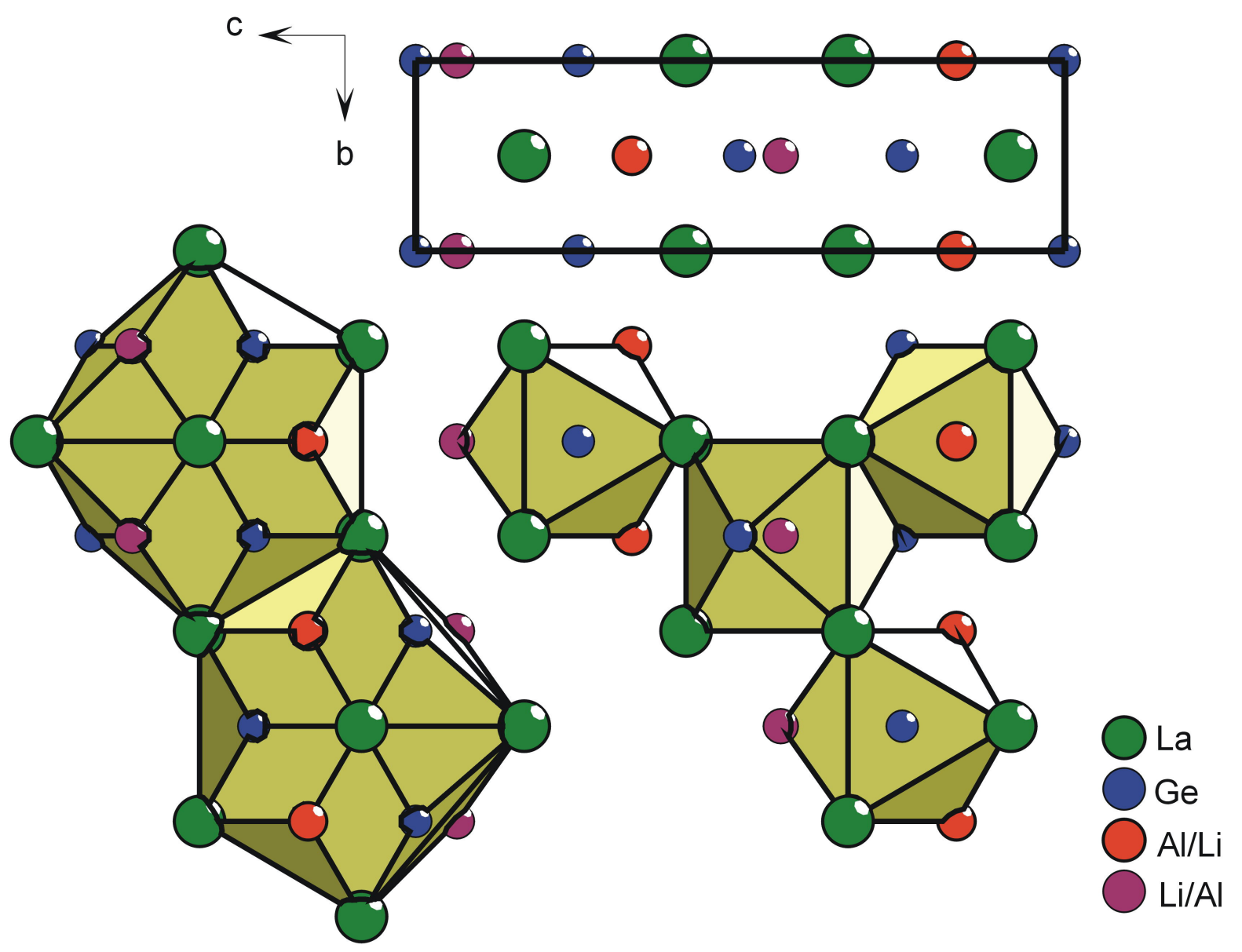

Fig. 1 Projection of the unit cell and coordination polyhedra of the atoms. 
Table 3 Interatomic distances $(\AA)$.

\begin{tabular}{|c|c|c|c|}
\hline $\mathrm{La}-\mathrm{Li}^{\mathrm{i}}$ & $3.09(4)$ & $\mathrm{Ge} 3-\mathrm{La} 2^{\mathrm{xi}}$ & $3.289(4)$ \\
\hline $\mathrm{La} 1-\mathrm{A} 16^{\mathrm{i}}$ & $3.09(4)$ & Ge3-La1 ${ }^{\text {xii }}$ & $3.3106(17)$ \\
\hline La1-A16 & $3.09(4)$ & Ge3-La1 $1^{\text {viii }}$ & $3.3106(17)$ \\
\hline $\mathrm{La} 1-\mathrm{Ge} 4^{\mathrm{ii}}$ & $3.286(4)$ & Ge3-La1 ${ }^{\text {ix }}$ & $3.3106(17)$ \\
\hline La1-Ge $4^{\mathrm{iii}}$ & $3.286(4)$ & Ge3-La1 ${ }^{\text {xiii }}$ & $3.3106(17)$ \\
\hline La1-Li5 $5^{\text {iv }}$ & $3.309(11)$ & Ge4-Al5 & $2.500(13)$ \\
\hline $\mathrm{La} 1-\mathrm{A} 15^{\mathrm{iv}}$ & $3.309(11)$ & Ge4-Li5 ${ }^{\text {xiv }}$ & $2.500(13)$ \\
\hline La1-Li5 ${ }^{\text {iii }}$ & $3.309(11)$ & $\mathrm{Ge} 4-\mathrm{A} 15^{\mathrm{xiv}}$ & $2.500(13)$ \\
\hline $\mathrm{La} 1-\mathrm{A} 15^{\mathrm{iii}}$ & $3.309(11)$ & Ge4-Al6 & $2.74(5)$ \\
\hline $\mathrm{La} 1-\mathrm{Li} 5^{\mathrm{v}}$ & $3.309(11)$ & Ge4-La1 ${ }^{\text {xiii }}$ & $3.286(4)$ \\
\hline $\mathrm{La} 1-\mathrm{A} 15^{\mathrm{v}}$ & $3.309(11)$ & Ge4-La1 ${ }^{\mathrm{xii}}$ & $3.286(4)$ \\
\hline $\mathrm{La} 2-\mathrm{Li}^{\mathrm{v}}$ & $3.29(2)$ & $\mathrm{Ge} 4-\mathrm{La} 2^{\mathrm{xii}}$ & $3.311(2)$ \\
\hline $\mathrm{La} 2-\mathrm{A} 15^{\mathrm{v}}$ & $3.29(2)$ & Ge4-La2 ${ }^{\text {viii }}$ & $3.311(2)$ \\
\hline $\mathrm{La} 2-\mathrm{Li} 5^{\mathrm{iv}}$ & $3.29(2)$ & Ge4-La2 $2^{\text {xiii }}$ & $3.311(2)$ \\
\hline $\mathrm{La} 2-\mathrm{Al} 5^{\mathrm{iv}}$ & $3.29(2)$ & Ge4-La2 $2^{\text {ix }}$ & $3.311(2)$ \\
\hline $\mathrm{La} 2-\mathrm{Ge} 3^{\mathrm{vi}}$ & $3.289(4)$ & $\mathrm{Al} 5-\mathrm{Ge} 4^{\mathrm{i}}$ & $2.500(13)$ \\
\hline $\mathrm{La} 2-\mathrm{Ge} 3^{\mathrm{vii}}$ & $3.289(4)$ & $\mathrm{A} 15-\mathrm{La} 2^{\mathrm{ix}}$ & $3.29(2)$ \\
\hline $\mathrm{La} 2-\mathrm{Ge} 4^{\mathrm{iii}}$ & $3.311(2)$ & A15-La2 ${ }^{\text {viii }}$ & $3.29(2)$ \\
\hline $\mathrm{La} 2-\mathrm{Ge} 4^{\mathrm{iv}}$ & $3.311(2)$ & Al5-La1 ${ }^{\text {viii }}$ & $3.309(11)$ \\
\hline $\mathrm{La} 2-\mathrm{Ge}^{\mathrm{v}}$ & $3.311(2)$ & Al5-La1 ${ }^{\text {xii }}$ & $3.309(11)$ \\
\hline $\mathrm{La} 2-\mathrm{Ge} 4^{\mathrm{ii}}$ & $3.311(2)$ & Al5-La1 ${ }^{\text {xiii }}$ & $3.309(11)$ \\
\hline La2-Li6 ${ }^{\text {iv }}$ & $3.42(2)$ & Al5-La $1^{\text {ix }}$ & $3.309(11)$ \\
\hline $\mathrm{La} 2-\mathrm{Al}^{\mathrm{iv}}$ & $3.42(2)$ & $\mathrm{Al} 6-\mathrm{Ge} 3^{\mathrm{iv}}$ & $2.38(2)$ \\
\hline Ge3-Li6 $6^{\text {viii }}$ & $2.38(2)$ & $\mathrm{Al} 6-\mathrm{Ge} 3^{\mathrm{v}}$ & $2.38(2)$ \\
\hline Ge3-Al6 viii & $2.38(2)$ & Al6-La1 ${ }^{\text {xiv }}$ & $3.09(4)$ \\
\hline Ge3-Li6 ${ }^{\text {ix }}$ & $2.38(2)$ & Al6-La2 ${ }^{\text {viii }}$ & $3.42(2)$ \\
\hline $\mathrm{Ge} 3-\mathrm{Al}^{\mathrm{ix}}$ & $2.38(2)$ & Al6-La2 $2^{x i i}$ & $3.42(2)$ \\
\hline Ge3-Al5 & $2.46(3)$ & $\mathrm{A} 16-\mathrm{La} 2^{\mathrm{ix}}$ & $3.42(2)$ \\
\hline $\mathrm{Ge} 3-\mathrm{La} 2^{\mathrm{x}}$ & $3.289(4)$ & Al6-La2 $2^{\text {xiii }}$ & $3.42(2)$ \\
\hline
\end{tabular}

Symmetry codes: (i) $x, y-1, z$; (ii) $x+1 / 2, y-1 / 2, z+1 / 2$; (iii) $x-1 / 2, y-1 / 2, z+1 / 2$; (iv) $x+1 / 2, y+1 / 2, z+1 / 2$; (v) $x-1 / 2, y+1 / 2, z+1 / 2$; (vi) $x, y+1, z+1$; (vii) $x, y, z+1$; (viii) $x-1 / 2, y-1 / 2, z-1 / 2$; (ix) $x+1 / 2, y-1 / 2, z-1 / 2$; (x) $x, y-1, z-1$; (xi) $x, y, z-1$; (xii) $x+1 / 2, y+1 / 2, z-1 / 2$; (xiii) $x-1 / 2, y+1 / 2, z-1 / 2$; (xiv) $x, y+1, z$.

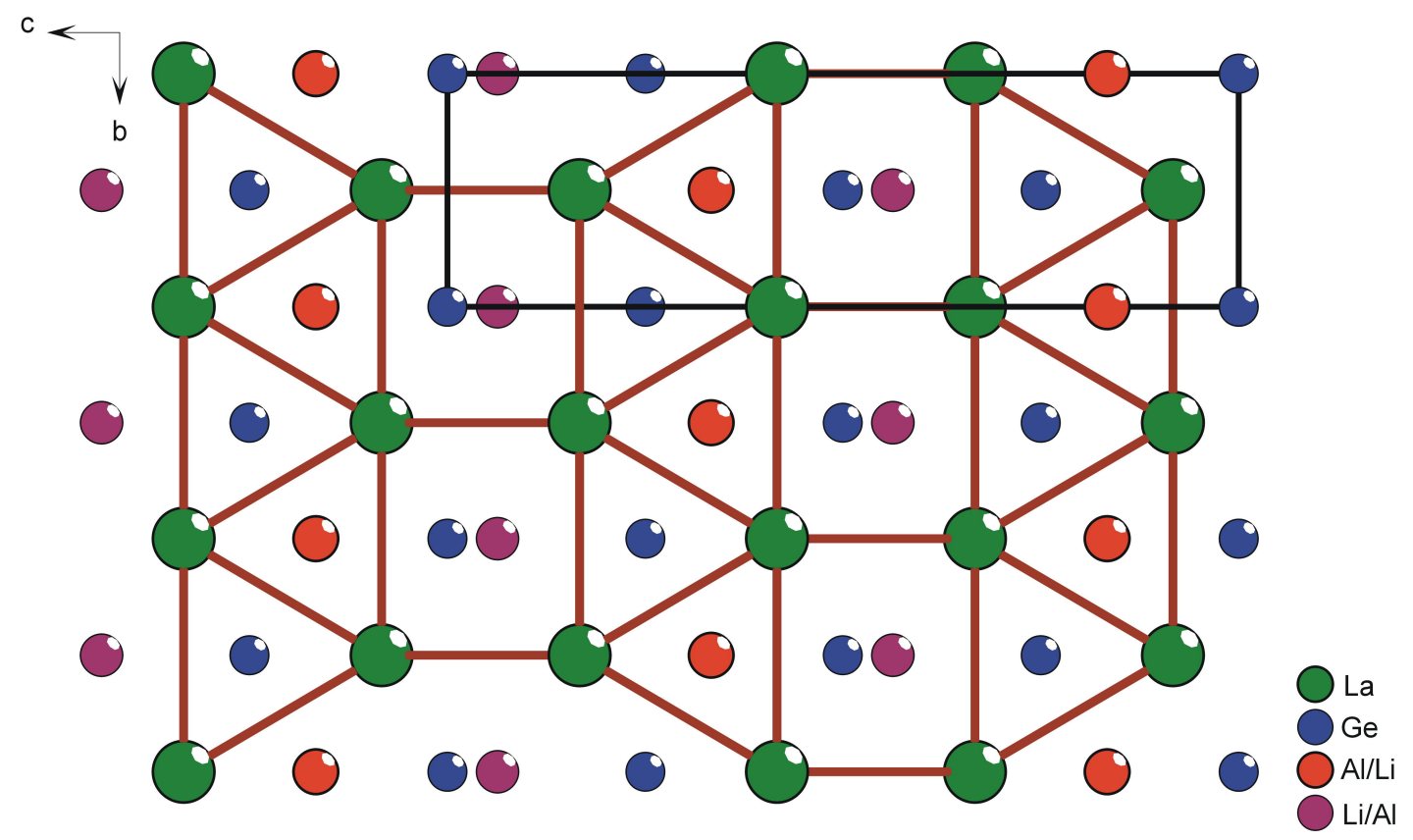

Fig. 2 Packing of trigonal prisms in the $\mathrm{La}_{2} \mathrm{LiAlGe}_{2}$ structure. 


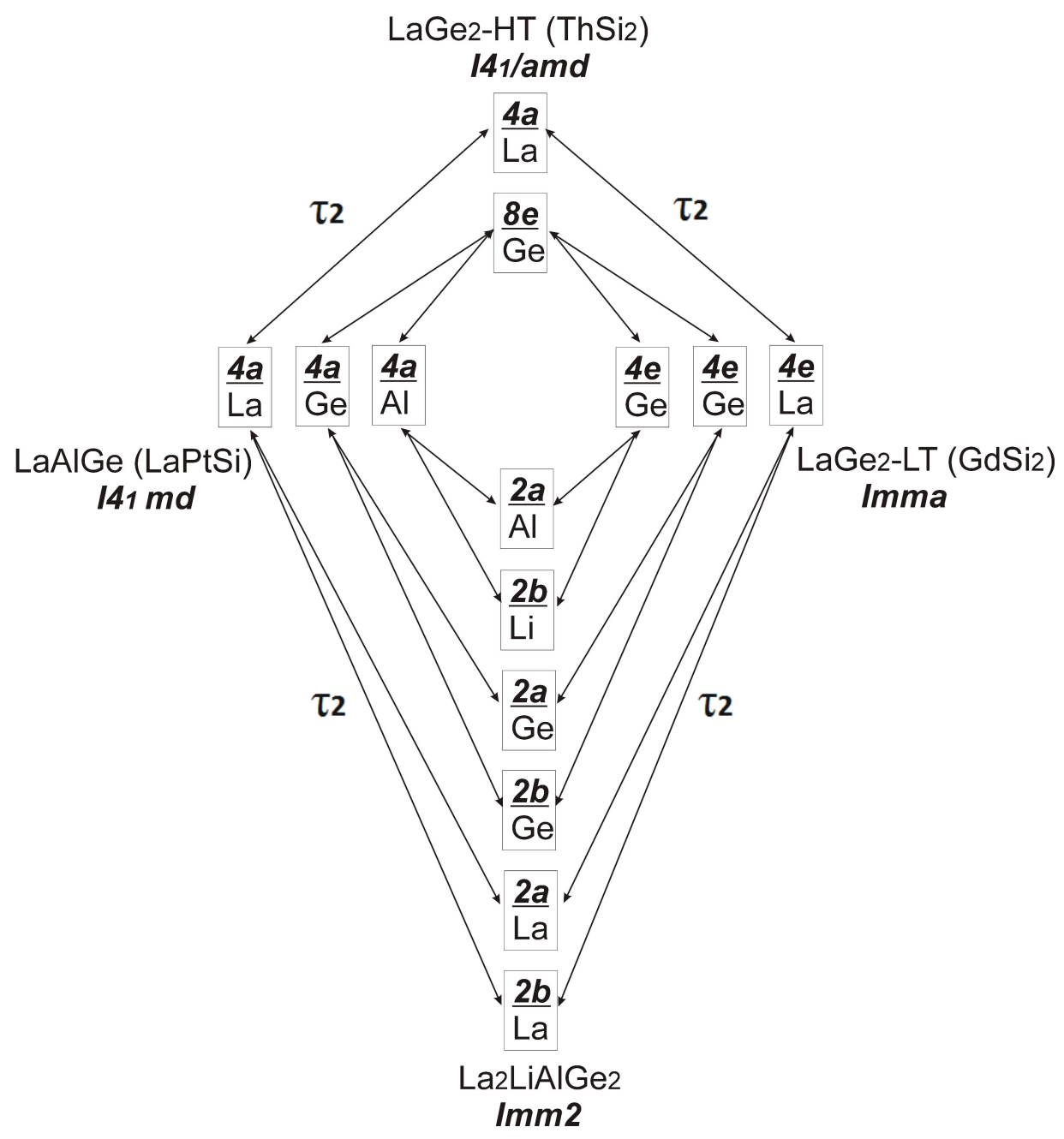

Fig. 3 Group-subgroup scheme on the basis of Bärnighausen formalism for the $\alpha$-ThSi $2, \alpha-\mathrm{GdSi}_{2}, \mathrm{LaPtSi}$, and $\mathrm{La}_{2} \mathrm{LiAlGe}_{2}$ structures.

Electronic structure calculations using the TB-LMTO-ASA program package [20] were performed for the ordered models of the ternary phase $\mathrm{LaAlGe}$ and the quaternary phase $\mathrm{La}_{2} \mathrm{LiAlGe}_{2}$. According to the results of the calculations, the lanthanum and lithium atoms donate their electrons to germanium atoms. The electron concentration is higher around the germanium, and slightly lower around the aluminum atoms, which partially lose their electrons (Fig. 4). The electron distribution around $\mathrm{Ge}$ is not spherical, but shifted a little toward the $\mathrm{Al}$ atoms. This indicates the presence of some covalent interaction between $\mathrm{Ge}$ and $\mathrm{Al}$ atoms. This suggestion is also confirmed by the almost $10 \%$ (compared with the sum of single-bond radii) reduction observed for the shortest interatomic distance between these atoms.

Taking into account the close values of the effective radii of aluminum and lithium atoms in intermetallic compounds, it can be concluded that nothing prevents their partial mutual substitution.

As for the previously studied $\mathrm{TbLi}_{1-x} \mathrm{Zn}_{x} \mathrm{Sn}_{2}$ phase [21], for the title compound we observe $\mathrm{Li} / M$ substitution, which shows that, in quaternary intermetallic phases, lithium readily forms statistical mixtures with atoms that have similar size and partly give their electrons to $p$-elements (such as Ge, Sn and others). The ability of lithium atoms to replace copper atoms has also been observed for the solid solutions $R E \mathrm{Li}_{x} \mathrm{Cu}_{2-x} \mathrm{Si}_{2}$ and $R E \mathrm{Li}_{x} \mathrm{Cu}_{2-x} \mathrm{Ge}_{2}$ [22].

The electron densities of states (DOS) of LaAlGe and $\mathrm{La}_{2} \mathrm{LiAlGe}$ are presented in Fig. 5. Semimetal behavior is observed for LaAlGe, because the density of states goes to zero at the Fermi level. The shift of this pseudo gap and the increase of the density of states at the Fermi level indicate an increase of the metallic character for the quaternary phase. The shift can also indicate a change of orbital overlap. 

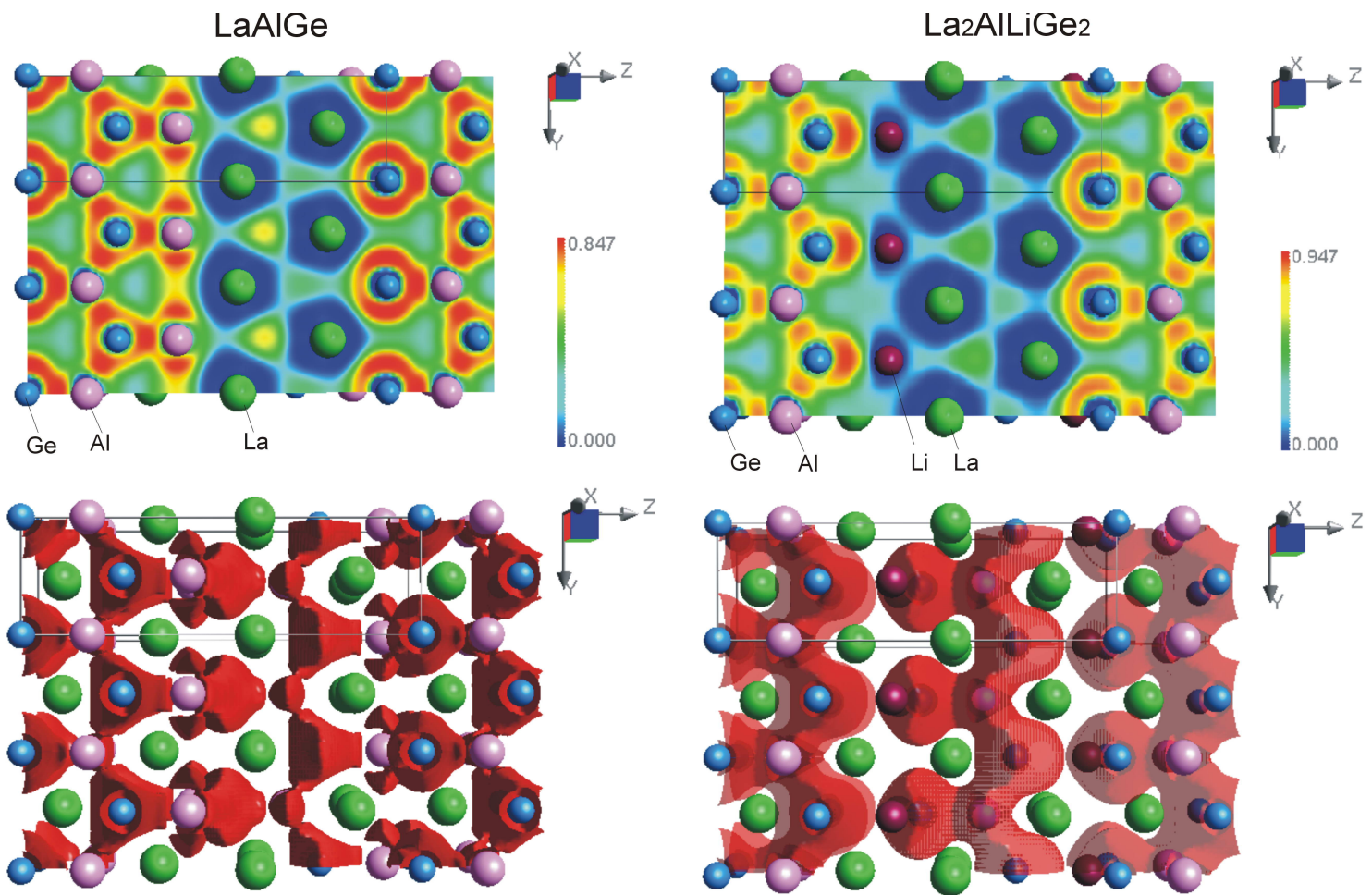

Fig. 4 The result of electron localization function calculations for ordered structure models of LaAlGe and $\mathrm{La}_{2} \mathrm{LiAlGe}_{2}$.

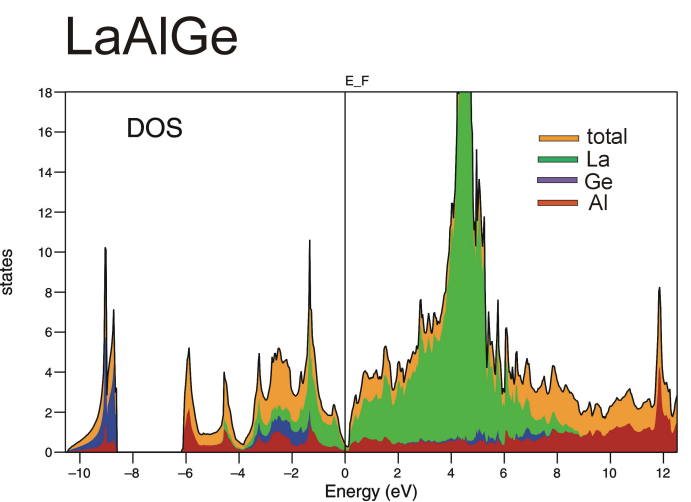

\section{La2AlLiGe2}

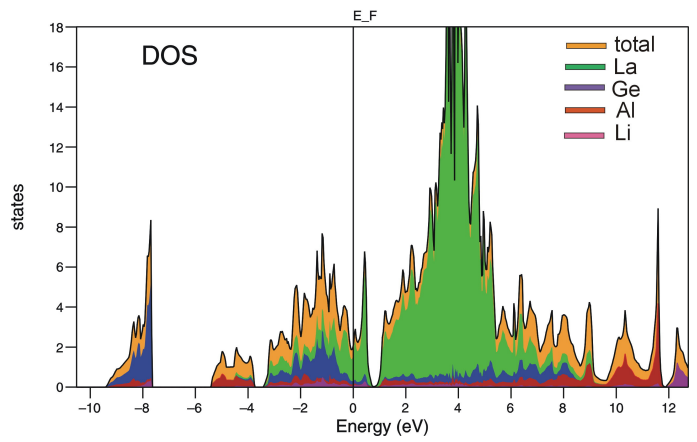

Fig. 5 The electron density of states of LaAlGe and $\mathrm{La}_{2} \mathrm{LiAlGe}_{2}$.

\section{Acknowledgements}

Financial support from the Ministry of Education and Science, Youth and Sport of Ukraine is gratefully acknowledged.

\section{References}

[1] K. Klepp, E. Parthé, Acta Cryst. B 38 (1982) 1105-1108.

[2] A.M. Guloy, J.D. Corbett, Inorg. Chem. 30 (1991) 4789-4794.

[3] E.I. Gladyshevskii, N.Z. Nakonechna, K. Cenzual, R.E. Gladyshevskii, J.L. Jorda, J. Alloys Compd. 296 (2000) 265-271.

[4] S. Pikus, E. Olszewska, I. Mel'nyk, R.E. Gladyshevskii, Powder Diffr. 19 (2004) 359-361.

[5] Z.T. Zhao, E. Parthé, Acta Cryst. C 46 (1990) 2276-2279.

[6] G. Brauer, A. Mitius, Z. Anorg. Allg. Chem. 249 (1942) 325-339.

[7] E.I. Gladyshevskii, J. Struct. Chem. (5) (1964) 523-529.

[8] V.V. Pavlyuk, V.K. Pecharskii, O.I. Bodak, Dopov. Akad. Nauk Ukr. RSR, Ser. B (2) (1989) 51-54. 
[9] V.V. Pavlyuk, V.K. Pecharskii, O.I. Bodak, Dopov. Akad. Nauk Ukr. RSR, Ser. A (7) (1986) 78-80.

[10] V.V. Pavlyuk, V.K. Pecharskii, O.I. Bodak, Kristallografiya 33 (1988) 43-45.

[11] V.V. Pavlyuk, V.K. Pecharskii, O.I. Bodak, V.A. Bruskov, Kristallografiya 33 (1988) 46-50.

[12] V. Pavlyuk, O. Bodak, Inorg. Mater. 28 (1992) 877-879.

[13] V. Pavlyuk, O. Bodak, Izv. Akad. Nauk SSSR, Metally. (6) (1992) 207-210.

[14] V. Pavlyuk, O. Bodak, V. Bruskov, Dopov. Akad. Nauk Ukr. (1) (1991) 112-114.

[15] I. Mayer, Y. Eshdat, Inorg. Chem. 7 (1968) 1904-1908.
[16] CrysAlis RED, Version 1.171, Oxford Diffraction, Oxford Diffraction Ltd, Abingdon, Oxfordshire, U.K., 2005.

[17] G.M. Sheldrick, Acta Crystallogr. A 64 (2008) 112-122.

[18] H.D. Flack, Acta Crystallogr. A 39 (1983) 876-881.

[19] H. Bärnighausen, MATCH Commun. Math. Chem. 9 (1980) 139-175.

[20] K. Andersen, Z. Povlovska, O. Jepsen, Phys. Rev. B 34 (1986) 51-53.

[21] A. Stetskiv, I. Tarasiuk, B. Rozdzynska-Kielbik, I. Oshchapovsky, V. Pavlyuk, Acta Crystallogr. E 68 (2012) i16.

[22] V. Pavlyuk, O. Bodak, D. Kevorkov, Dopov. Akad. Nauk Ukr. (9) (1993) 84-87. 